Rolls and the Lords Justices Lopes and Kay. ${ }^{1}$ All the judges emphatically condemn the action of the plaintiff's legal advisers in prosecuting this appeal. The same course could have been followed against any medical man in the kingdom. It is probable that the emphatic condemnation of the judges will, to some extent, stop such proceedings in future. This, however, is not much balm to those who have to bear the brunt of the plaintiff's action. Although the appeal was dismissed with costs, and the verdict for the defendants upheld, we are advised that there is no chance of recovering anything. If $I$ were alone interested in the case, I should not now write to you; but my colleague feels it heavily, and, in my opinion, we ought not to bear this heavy charge withont an attempt being made on the parb of the members of the medical profession to lighten the burden thrown upon us. There is a case somewhat similar reported in yesterdays papers which ought to be treated in a similar manner, as until the law is altered the medical profession should surely determine to defend its members from the possible ruin which such proceedings might entail as a consequence of honestly performing a professional duty. I am not aware of the result of the appeal of Drs. Sutherland and Austin in your columns, but I thank them for having made it.

I am, Sirs, yours obediently,

Heath Lodge, Croydon, Dec. 5th, 1891. AlFRED CARPENTER.

** It is impossible to deny that the case of the defendants in the above action is very hard, and such as to call for a wide expression of sympathy in the profession. It is little satisfaction to get verdicts and costs against plaintiffs and to have no chance of recovering the latter. We earnestly appeal to the profession to contribute to the expenses of these gentlemen. Dr. Carpenter does not write in his own interest so much as out of consideration to his colleague, who, he says, feels the burden heavily. As we have before intimated, we shall be glad to receive any sums in furtherance of this object.-ED. L.

\section{UNILATERAL PAROTITIS.}

\section{To the Editors of THE LANCET.}

SIRS,-During the last six years three cases of unilateral parotitis have occurred in Westminster Hospital-two under my own care and one under that of a colleague-during strict treatment by nutrient enemata for gastric ulcer. In all there was some pyrexia and in one severe constitutional disturbance with suppuration of the gland. It is the belief of some that secondary parotitis may arise from retained and decomposed secretion owing to blocking of the ductus stenonis in connexion with dryness of the buccal mucosa. I am nnaware of any reported instances of parotitis appearing during rectal feeding, and, being inclined to think that the above-mentioned causal association may be illustrated by these cases, I write with the object of obtaining information from others on this point. I am, Sirs, yours truly,

Harley-street, W., Dec. 7th, 1891. H. B. DoNkIN.

\section{"A CASE IN MEDICAL JURISPRUDENCE."}

\section{To the Editors of THE LANCET.}

SIRS,-Dr. Martindale C. Ward will find a parallel to his case of complete disappearance of the viscera (in a corpse which had long lain dead in an empty house) in the famous Arran murder case. The body of Mr. Rose, the victim, was found to be completely eviscerated, presumably by the action of maggots. The amount of material which these growing larval insects consume is marvellous, and their huge relative increase is a familiar biological fact. Little wonder that the viscera should disappear completely from any body in six months' time, with generation after generation of maggots feeding on its viscera. "Post.mortem digestion" surely could not act on the whole of the organs, and putrefaction alone will not account for the total clearing out of the cavities. Besides, the body in Dr. Ward's case must have lain in the house all through the summer, when the generative processes of flies are in full swing. I am, Sirs, yours truly,

Edinburgh, Dec. 5th, 1891. ANDREW WIISON.

P.S.-If Dr. Ward will refer to the reports of the Arran murder trial, he will be able to compare the condition of the victim's body set forth by Drs. Littlejohn and Gilmour with the details he himself gives of the case at Teddington.

\section{THE CENSURE OF A MEDICAL OFFICER OF}

\section{A WORKHOUSE BY A JURY.}

\section{To the Editors of THE LANCET.}

SIRs,-Perhaps you will allow me the opportunity of correcting some misconceptions into which you have fallen in commenting on the above case in your last issue. They have doubtless arisen from the kind of reporting which, in my experience, is so common in dealing with medical matters. It is not surprising, however, in this instance, from the manner in which the inquest was conducted, that the reporters had some difficulty in discriminating between the evidence given by witnesses and the loudly expressed foregone conclusions at which a portion of the jury had obviously arrived. The first point $I$ should like to correct is that I am stated to have thought the patient actually dying, and thereupon gave warning to the friends. What I did think was that from the patient's general condition a rapid alteration for the worse might be expected, and this $I$ endeavoured to avert by treatment. The reports in the public prints which you have evidently consulted make much of the bruising of the patient's face and neck, and the conflict of evidence about them. As a matter of fact, there were no bruises of any description about either face or neck, and one can only conclude such had been conjured up in the inflamed minds of the jury. All that was seen on the face and neck by the friends and myself were some scratches, doubtless caused by the finger-nails of the patient before he was restrained. Unfortunately, the coroner did not view the body, and so was carried away by the exaggerated expressions of the jury. The coroner thought fit to take me to task about the writing of the certificate, but I may say that he afterwards admitted that I was perfectly within my right in doing so, and such is my present conviotion. The fact is that the whole case was recklessly exaggerated for some reason or other; and not only was the result arrived at, as you say, carrying matters to an extreme, but, one can only imagine, was premeditated. As to want of attention on my part, the press do not state (which was given in evidence) that I saw the patient four times in the twenty-four hours preceding my last visit; and he was seen also by the assistant medical officer.

I am, Sir, yours obediently,

Bancroft-road, N.E., Dec. 9th, 1891. A. H. RoBINSON.

\section{TREATMENT OF ENTERIC FEVER.}

\section{To the Editors of THE LANCET.}

SIRS, - In the current number of THE LANCET there is an interesting account of the treatment of enteric fever by Dr. Pearson. As he is now in this country, I should like to ask him, through the medium of THE LANCET, what was the cause of the sudden outbreak of the epidemic which he mentions? Was it traced to its usual sourcespollution of the water or milk which was consumed? There is a peculiar interest attaching to this question, because it so happens that at the very time of this outbreak in Cape Colony we in England experienced our first visitation of influenza-viz., November, 1889. I am now writing on this subject, and should be glad if Dr. Pearson will give us more particulars. Strange that both he and I should have owed our success in the respective treatment of these two diseases to the use of a compound of chlorine, he giving chlorinated soda for one, and I the chloride of ammonium for the other.

Since writing the above I have read the remarks of Dr. Leeson on influenza, also in THE LANCET, and find that he looks upon isolation as sufficient to prevent its spread. He mentions that the 300 children in the orphanage thus escaped. Will Dr. Leeson kindly tell us whether he had any children under treatment outside the orphanage? In the first epidemic of influenza $I$ do not remember a single case where a child suffered from it.

I am, Sirs, yours faithfully,

London, Dec. 7th, 1891.

GeORGe HerRing. 